\title{
ResearchOnline@JCU
}

This is the author-created version of the following work:

Thorley, Craig, and Kumar, Devvarta (2017) Eyewitness susceptibility to cowitness misinformation is influenced by co-witness confidence and own selfconfidence. Psychology, Crime \& Law, 23 (4) pp. 342-360.

Access to this file is available from:

https://researchonline.jcu.edu.au/46877/

Please refer to the original source for the final version of this work:

http://dx.doi.org/10.1080/1068316X.2016.1258471 
Eyewitness susceptibility to co-witness misinformation is influenced by co-witness confidence and own self-confidence

\author{
Craig Thorley ${ }^{1}$, Devvarta Kumar ${ }^{2}$ \\ ${ }^{1}$ Psychological Sciences, University of Liverpool, Liverpool, UK \\ ${ }^{2}$ Department of Clinical Psychology, National Institute of Mental Health and Neurosciences, \\ Bangalore, India
}

Address for correspondence:

Dr. Craig Thorley

Psychological Sciences

Eleanor Rathbone Building

University of Liverpool

Liverpool, L69 7ZA

UK

Phone: +44 (0)151 7941106

Email: craig.thorley@liverpool.ac.uk

Authors Note: We thank Jack Briggs, Neil Dobbie, Georgia Connolly, and Jane L. Sayers, and Dr. Katherine Twomey for assistance with creating the test materials for this project. 


\begin{abstract}
If an eyewitness is exposed to a co-witness statement that incorrectly blames an innocent bystander for a crime, the eyewitness can be influenced by this statement and also blame the innocent bystander for the crime. This effect is known as blame conformity. In two studies, we examined whether or not this effect is influenced by the degree of confidence a co-witness expresses in her incorrect statement (Study 1) and an eyewitness’s own level of self-confidence (Study 2). Participant eyewitnesses first watched a crime video featuring a perpetrator and an innocent bystander, then read a co-witness statement about the crime that either correctly blamed the perpetrator, incorrectly blamed the innocent bystander, or blamed nobody (a control condition). They were then asked who committed the crime. In Study 1, participants who read an incorrect statement were at increased risk of engaging in blame conformity when the co-witness expressed a high level of confidence, compared to a low level of confidence, in the accuracy of her statement. In Study 2, participants who were lowest in self-confidence were at increased risk of engaging in blame conformity. The theoretical underpinnings of these effects are considered.
\end{abstract}

Keywords: blame conformity; eyewitness memory; memory conformity; social contagion; confidence 


\section{Eyewitness susceptibility to co-witness misinformation is influenced by co-witness confidence and own self-confidence}

Borchard (1932), Garrett (2011), and Porter (2007) document hundreds of legal cases where individuals have been accused, tried, convicted, imprisoned, and sometimes executed, for crimes they did not commit. When DNA evidence was introduced into the criminal justice system in 1986, it offered appeal courts a means of testing the veracity of past convictions (Williams \& Johnson, 2013). To date, there have been 336 DNA exonerations in the United States. In $70 \%$ of these cases the exonerated were convicted, at least in part, as a result of mistaken eyewitness identification (Innocence Project, 2015). A large literature exists examining the reasons why mistaken identifications occur (see Lampinen, Neuschatz, \& Cling, 2012). Within this literature it has been found that eyewitnesses can spontaneously mistakenly identify an innocent bystander as the perpetrator of a crime (e.g., Buckhout, 1974). It has also been demonstrated that eyewitnesses are at increased risk of blaming an innocent bystander for a crime after exposure to a co-witness statement that incorrectly suggests this person was the perpetrator (Thorley, 2015). Here, we present two studies that examine whether or not this effect is influenced by the degree of confidence a cowitness expresses in her belief that an innocent bystander was the perpetrator of a crime (Study 1) and an eyewitness's own level of self-confidence (Study 2).

\section{Memory conformity and blame conformity}

If eyewitnesses encounter post-event misinformation (PEM) about a crime then they can incorporate this misinformation into their subsequent descriptions of it (see Davis \& Loftus, 2007). The present studies focus on PEM deriving from a co-witness. This is important as most crimes have multiple eyewitnesses (Paterson \& Kemp, 2006a; Skagerberg \& Wright, 2008) and PEM can be transferred between these eyewitnesses 'directly' during conversations about the crime or 'indirectly' through a third party, such as a police officer, who informs one eyewitness about what a co-witness has said (Luus \& Wells, 1994). Co-witness PEM is a concern for legal professionals as there are several documented criminal cases where direct and indirect exposure to it has 
contaminated an eyewitness's subsequent legal testimony and compromised a police investigation (see Gabbert, Wright, Memon, Skagerberg, \& Jamieson, 2012; Wright, Memon, Skagerberg, \& Gabbert, 2009). When one individual alters their memory report of an event to be consistent with another's differing memory report of the same event, this is known as memory conformity (Wright, Self, \& Justice, 2000) or social contagion of memory (Roediger, Meade, \& Bergman, 2001).

Researchers have developed a number of techniques to induce memory conformity in the laboratory. Modelling real life scenarios, participants in these studies can be exposed to coparticipant PEM directly or indirectly (see Gabbert, Memon, Allan, \& Wright, 2004; Meade \& Roediger, 2002, for examples of both). A popular method of direct exposure involves having participant and confederate pairs study and remember the same information together. During the collaborative remembering test, the confederate deliberately introduces PEM. On subsequent individual testing, participants succumb to memory conformity by including the PEM in their memory reports. A popular method of indirect exposure is to have individual participants study some information, then have them read or listen to a hypothetical co-participant's erroneous recall of this same information, and then have them complete an individual memory test. Again, participants succumb to memory conformity and incorporate the PEM into their memory reports. Several studies have also examined whether directly or indirectly encountered co-witness PEM produces stronger memory conformity effects and no differences are typically observed (e.g., Blank et al., 2013; Meade \& Roediger, 2002; Paterson \& Kemp, 2006b, but see Gabbert et al., 2004).

Wright et al. (2009) suggest memory conformity occurs for one of three reasons. First, it can occur as a result of normative influence, whereby a participant privately knows that the PEM is inaccurate but includes it in a memory report out of a desire to avoid any potential conflict with the source. Second, it can occur as a result of informational influence, whereby a participant is unsure if the PEM is accurate but reports it anyway out of a desire to be correct. Third, it can occur as a result of false remembering, whereby a participant forms an episodic memory of the PEM and genuinely 
believes it is accurate. Individual participants within the same study may succumb to memory conformity for different reasons (e.g., Gabbert, Memon, \& Wright, 2007; Meade \& Roediger, 2002).

Taking inspiration from the memory conformity literature, Thorley (2015) recently examined whether or not exposing an eyewitness to a co-witness statement that incorrectly blames an innocent bystander for a crime can increase the likelihood of the eyewitness subsequently blaming the innocent bystander for the crime. In that study, nearly $43 \%$ of participants who read such a statement from a young female co-witness also blamed the innocent bystander. In comparison, fewer than $8 \%$ of participants who read a correct statement or a control statement (where no blame was mentioned) from this same co-witness blamed the innocent bystander. Participants' attributions of blame can therefore be influenced by PEM deriving from a co-witness (see also Thorley \& Rushton-Woods, 2013). This specific type of memory conformity is called blame conformity and is the focus of present studies. As both effects are conceptually similar, they likely have similar underlying causes. Blame conformity is important as it could result in the police wrongfully arresting an innocent bystander for a crime and that could either slow down an investigation or, in extreme cases, result in an erroneous conviction.

\section{Co-witness confidence and memory conformity}

Eyewitnesses can display high levels of confidence in the PEM they claim to remember (e.g., Loftus, Donders, Hoffman, \& Schooler, 1989; Loftus, Miller, \& Burns, 1978; Luna \& Migueles, 2009). Moreover, people perceive highly confident eyewitnesses as more accurate than less confident eyewitnesses (see Penrod \& Cutler, 1995) and more readily believe the testimony of a very confident but inaccurate eyewitness over that of a less confident but more accurate eyewitness (e.g., Brewer \& Burke, 2002; Lindsay, Wells, \& Rumpel, 1981). Thus, if a co-witness expresses a high degree of confidence in the accuracy of his or her errors when describing a crime, an eyewitness may believe this PEM is accurate and incorporate it into his or her own subsequent memory report of the crime. 
Goodwin, Kukucka, and Hawks (2013) have examined whether or not a co-witness’s confidence in his or her recall errors influences memory conformity. In their study, participant and confederate pairs watched a crime video and then took turns answering questions about it, with both providing answers to the same question aloud before moving on to the next question. The confederate responded first for half of the questions and made six deliberate recall errors. Confidence ratings of 1 (low confidence) to 10 (high confidence) were also provided for each answer. Half of the participants worked with a confederate who expressed low confidence in the PEM (2's or 3's on the confidence scale) and half worked with a confederate who expressed high confidence in the PEM (8's or 9's). Participants were more likely to engage in memory conformity with the high confidence confederate by repeating this person's incorrect answers (see also Ost, Ghonouie, Cook, \& Vrij, 2008, and Wright et al., 2000). Participants' confidence in these incorrect answers also mirrored those of the confederate, suggesting a confidence conformity effect.

Surprisingly, Goodwin et al. (2013) also found little evidence of memory conformity (and, therefore, confidence conformity) when participants completed a post-collaborative individual memory test. Goodwin et al. suggest that participants primarily engaged in memory conformity and confidence conformity during collaboration as a result of normative influence. These effects then disappeared on the subsequent individual memory test as participants recalled in private and were no longer concerned about disagreeing with the confederate. The complete elimination of memory conformity on subsequent individual tests is, however, unusual. In many memory conformity studies, participants continue conforming when tested alone (see Gabbert et al., 2012; Wright et al., 2009). Re-examining the impact of co-witness confidence on memory conformity when participants are tested alone would therefore be beneficial in case Goodwin et al.'s null effects were peculiar to their study.

\section{Eyewitness self-confidence and memory conformity}

Self-confidence is typically decomposed into general self-confidence and specific selfconfidence (see Oney \& Oksuzoglu-Guven, 2015, for a detailed overview). General self-confidence 
is the extent to which a person believes in their own overall abilities irrespective of any specific context. Specific self-confidence is a person's confidence in a specific ability in a specific domain at a given point of time. Both types of self-confidence are related in the sense that general selfconfidence is an aggregate of specific self-confidences. General self-confidence, however, is fairly stable over time whereas specific self-confidence is unstable as it is based on task-specific experiences and is updated each time the specific task is completed. Consequently, general selfconfidence is seen as a personality trait and specific self-confidence as a personality state. The present research focusses on general self-confidence only.

To date, only one memory study has attempted to directly measure the impact of selfconfidence on susceptibility to PEM. In that study, Vrij and Bush (2000) assessed younger (5-6 year olds) and older (10-11 year olds) children's self-confidence, presented them with a cartoon, and then had them answer a series of factual and misleading questions (i.e., questions relating to events that did not take place) about the cartoon. It was found that the more self-confident the children were, the fewer inaccurate answers they gave to the misleading questions. Unfortunately, selfconfidence was not assessed using a validated measure in that study (see p.134), with the authors using six items from a self-esteem questionnaire that they state "in our view indicate self-confidence" (p.131). This study therefore provides some tentative evidence to suggest self-confidence may impact upon susceptibility to memory conformity/blame conformity but a more direct investigation of this issue is needed.

\section{The current studies}

Across two studies, we will examine the impact of co-witness confidence and own selfconfidence on susceptibility to blame conformity. In both, participant eyewitnesses will watch a crime video and then read a co-witness statement that correctly blames the perpetrator for the crime, incorrectly blames an innocent bystander, or blames nobody. Participants will then indicate who they believe committed the crime. In Study 1, the co-witness will express either high or low confidence in her statement. In Study 2, the co-witness statement will contain no expression of 
confidence and, instead, participants own levels of general self-confidence will be assessed. In both studies, participants will also rate their own confidence in their blame judgements.

Study 1 is a conceptual re-examination of Goodwin et al.’s (2013) observation that cowitness confidence has no impact upon the degree to which participant eyewitnesses engage in memory conformity when tested alone. As mentioned, Goodwin et al. found no evidence of this, but they also found no evidence of any memory conformity when participants were tested alone. Such a finding is unusual. We will therefore re-examine this issue using the (conceptually similar) blame conformity paradigm. Study 2 is the first to examine whether or not general self-confidence, as assessed by a validated self-confidence questionnaire, can predict whether or not a person engages in memory conformity/blame conformity. This study could therefore make a theoretical contribution to the literature by identifying a previously unidentified mechanism that moderates memory conformity/blame conformity.

Several hypotheses can be proposed for both studies. For Study 1, it is anticipated that participants will be more likely to engage in blame conformity with a high confidence co-witness than a low confidence co-witness. This is based upon past observations that participants are more likely to engage in memory conformity with a high confidence co-witness than a less confident one (Goodwin et al., 2013; Ost et al., 2008; Wright et al., 2000) and that memory conformity/blame conformity effects occur when participants are tested alone (see Gabbert et al., 2012; Thorley, 2015; Wright et al., 2009). This prediction, however, is tentative as memory conformity effects did not occur in Goodwin et al.’s (2013) study when participants were tested alone. It is also anticipated that participants who engage in blame conformity with a high confidence co-witness will have more confidence in their blame judgements than those who engage in blame conformity with a low confidence co-witness. This is based upon the Goodwin et al.'s observation that participants engage in confidence conformity.

For Study 2, it is tentatively expected that participants higher in general self-confidence will be less susceptible to blame conformity. This is based upon past research showing that children 
higher in self-confidence are less likely to answer misleading questions incorrectly (Vrij \& Bush, 2000). Finally, it is unclear as to whether or not participants' own general self-confidence will be associated with their confidence in their blame judgements. This issue has not previously been examined and is exploratory.

\section{Study 1}

Study 1 examined whether or not participant eyewitnesses are at increased risk of blaming an innocent bystander for a crime after reading an incorrect statement from a co-witness who expresses with a high degree of confidence, compared to a low degree of confidence, that the innocent bystander was the perpetrator.

\section{Method}

\section{Participants}

There were 288 participants, aged 19-67 ( $M=34.15, S D=10.14$; 55\% male, 45\% female). They were recruited via Amazon’s Mechanical Turk, which is an online labour market where participants complete tasks for pay (see Casler, Bickel, \& Hackett, 2013; Paolacci \& Chandler, 2014). All were located in the United States, spoke fluent English, had completed at least 1000 previous tasks, and had a 95\% or greater approval rating for these tasks. All were paid US\$2.

\section{Design}

There was a 3 x 2 between-subjects design with 48 participants in each condition. The first independent variable was co-witness statement type. This varied according to whether the cowitness blamed no one for the crime (a control statement), correctly blamed the perpetrator for the crime, or incorrectly blamed an innocent bystander for the crime. The second independent variable was the co-witness's level of confidence in the accuracy of the statement. For this, the co-witness expressed high confidence or low confidence. The dependent variables in this study were the participants' attributions of blame for the crime and their confidence in these attributions. Both dependent measures are described in the Stimuli section. 


\section{Stimuli}

Study 1 utilised a crime video, two filler videos, a co-witness statement about the crime, a 10-item recognition memory test about the crime, and a co-witness confidence manipulation check question. Each is now described in turn.

The crime video depicts a young female entering a park and sitting down on a bench. Once seated, she places her bag on the bench, removes a book from it, and begins to read. As she is reading, two young men can be seen sat nearby on separate benches. One is wearing a light blue polo shirt and is reading a book. The other is wearing a black and red polo shirt and is playing with his mobile phone. After a few moments, the female receives a phone call and paces around the park. As she does this, her bag is left unattended on the bench and she is facing away from it. The man in the black and red polo shirt notices this, walks over to the bag, picks it up, and walks out of the park. As this is happening, the man in the blue polo shirt is reading his book, unaware of the crime. When the student finishes her phone call, she turns to face the bench, notices her bag is gone, and looks around for it. The video lasts 1 min 49 sec. See Figure 1 for screenshots.

\section{INSERT FIGURE 1 HERE}

The two 10 min filler videos were excerpts from the BBC television series Coast, which is a show about the British coastline. Their content does not overlap with the crime video.

The co-witness statement was preceded by a short paragraph containing orienting information. Specifically, participants were informed that "The bag theft you witnessed in the first video took place in a park at a university. You will next read an eyewitness statement that was provided to the campus security about the bag theft. The eyewitness is a female student at the university who was in the park at the time of the crime but who was sat out of view in the video". The statement was written in the form of an interview between the security guard and the cowitness. There were six versions of the statement. In each, the co-witness provided an identical, and accurate, physical description of the victim and the two men in the park, the actions of the victim throughout the video, and the actions of the two men up until the point of the theft. These six 
statements only differed with regards to who the co-witness blamed for the crime and how confident she was in the accuracy of her statement.

Two of the co-witness's statements provided a correct account of the theft, accurately stating "the man in the black and red polo shirt” stole the bag. There were also two incorrect statements, incorrectly stating "the man in the light blue polo shirt" stole the bag. Finally, two of the co-witness statements were control statements that stated "one of the men" stole the bag but did not indicate which. The control statements are important as they provide a measure of how accurately participants remembered who was to blame for the crime in the absence of any (erroneous or correct) co-witness influence. Towards the end of each statement, the security guard asked the co-witness "If I were to ask you on a scale of 1-10 how confident you are in your description of the crime, what would you say?’. In one of the correct statements, incorrect statements, and control statements, she responded “Eight. I am very confident”. In the remaining three statements, she responded "Two. I am not very confident”.

The 10-item recognition memory test contained nine general questions related to different aspects of the crime video such as the colour of the gates in the park. None of these general questions related to the theft. These general questions were included to disguise the fact that the study was interested in attributions of blame for the crime and responses to them were not analysed ${ }^{1}$. The tenth question was the critical blame question. Specifically, participants were asked "Who stole the bag from the victim?”. Each question had four possible response options, one of which was always 'don't know'. The remaining response options for the critical question were "The man in the light blue polo shirt”, “The man in the red and black polo shirt”, and "neither man”. After answering each question, participants rated on a scale of 0-10 how confident they were in their answer (zero indicated no confidence and 10 indicated certainty).

A co-witness confidence manipulation check question was also included at the end of the study to ensure participants paid attention to the co-witness's confidence in her statement. Specifically, participants were asked "When interviewed by the campus security, how confident was 
the eyewitness in her statement on a scale of 1 - 10 ?”. The response options were "2 out of 10 ”, “5 out of 10", "8 out of 10" or “don't know”. If participants failed to answer this question correctly their results were excluded from all analyses.

\section{Procedure}

Testing occurred in one online session lasting approximately 30 mins. First, onscreen instructions informed participants that they would be required to watch three short videos and that their enjoyment of these videos would be assessed. No mention was made of any memory tests. All participants were then asked to don headphones and the crime video was shown. When the crime video finished, a second (filler) video was shown. After the filler video, participants read the orienting information about the eyewitness statement and had a fixed period of 2 min to read the statement. After this, the statement disappeared and participants were informed that they would watch another (filler) video. After this video, onscreen instructions informed participants that they would be required to answer questions about the crime video. The first of the 10-item multiple choice questions then appeared. Each question was presented separately and, immediately after each question, participants rated their confidence in their answer. During this test, the critical question always appeared eighth. After answering all 10 questions, participants were asked the manipulation check question. The study then ended.

\section{Results and Discussion}

\section{Co-witness confidence manipulation check}

Overall, 94\% of participants answered this question correctly. Those participants who answered this question incorrectly or responded “don’t know” were excluded from all further analyses. After exclusion, there were 48 participants in the high confidence control statement condition, 46 in the high confidence correct statement condition, 44 in the high confidence incorrect statement condition, 45 in the low confidence control statement condition, 44 in the low confidence correct statement condition, and 44 in the low confidence incorrect statement condition. 


\section{Blame conformity analyses}

Two 4 x 3 Exact Pearson Chi-Square tests were used to ascertain if there was an association between who participants blamed for the crime (the innocent bystander, the perpetrator, neither, or don't know) and who the co-witness blamed for the crime (the innocent bystander, the perpetrator, or nobody). The first test examined the attributions of blame of those participants who read the high confidence co-witness statement and second examined attributions of blame of those participants who read the low confidence co-witness statement. Exact Chi-Square tests were used as data screening revealed several contingency table cells had expected counts of less than 5 (for readers unfamiliar with Exact tests, see Mehta \& Patel, 2011). The full range of observed frequencies (as percentages) can be seen in Table 1.

After reading the control statement from the high confidence co-witness, 8.33\% of participants blamed the innocent bystander for the crime whereas $83.33 \%$ blamed the perpetrator. A similar trend was observed after participants read the correct statement from the high confidence cowitness, with $2.17 \%$ blaming the innocent bystander and $97.83 \%$ blaming the perpetrator. Participants were therefore largely correct in their attribution of blame in these conditions. In contrast, when participants read the incorrect high confidence co-witness statement, 34.09\% blamed the innocent bystander whereas 59.09\% blamed the perpetrator. This latter result implies blame conformity occurred. In line with this, there was a significant association between who the high confidence co-witness blamed for the crime and who participants blamed, $\chi^{2}(6, n=138)=31.11$, Exact $p=.001$, Cramer's $V=.34$. The standardised residuals were examined to determine which cells contained frequencies that differed from those expected if there was no association between who the co-witness blamed and who participants blamed (for readers unfamiliar with standardised residuals, see Field, 2013). To be statistically significant at the .05 alpha level, the standardised residuals need to be greater than $1.96 \mathrm{z}$-scores. After reading an incorrect high confidence cowitness statement, participants blamed the innocent bystander more often than expected $(z=3.40)$. This confirms that participants engaged in blame conformity in this condition. After reading the 
high confidence co-witness correct statement, fewer participants than expected blamed the innocent bystander $(z=2.20)$. This latter result occurred as fewer participants in this condition blamed the innocent bystander for the crime than those who read the control statement and the incorrect statement. No other cells contained values that significantly differed from the expected frequencies (all z’s $=<1.96)$.

After reading the control statement from the low confidence co-witness, $6.67 \%$ of participants blamed the innocent bystander for the crime and $82.22 \%$ blamed the perpetrator. A similar trend was observed after participants read the correct statement from the low confidence cowitness, with $6.82 \%$ blaming the innocent bystander and $86.36 \%$ blaming the perpetrator. Participants were therefore, once again, largely accurate in their attribution of blame in these conditions. In contrast, when participants read the incorrect low confidence co-witness statement, 22.22\% blamed the innocent bystander and 73.33\% blamed the perpetrator. There was, therefore, a trend towards blame conformity. There was a borderline significant association between who the low confidence co-witness blamed for the crime and who participants blamed, $\chi^{2}(6, n=134)=$ 10.48 , Exact $p=.07$, Cramer's $V=.20$. As this analysis only approached significance, the standardised residuals were examined. After reading the incorrect low confidence co-witness statement, participants blamed the innocent bystander for the crime more often than expected $(z=$ 2.00). This result therefore suggests that participants engaged in blame conformity with the low confidence co-witness after reading her incorrect statement. No other cells contained values that significantly differed from the expected frequencies (all z’s $=<1.96$ ).

Combined, these results demonstrate that participants engaged in blame conformity in this study. This effect, however, was larger when the co-witness expressed high confidence (Cramer's V $=.34$ ), compared to low confidence (Cramer's $V=.20$ ), in the accuracy of her incorrect statement.

INSERT TABLE 1 HERE

\section{Blame confidence analyses}

To examine for confidence conformity, the confidence ratings of the participants who 
blamed the innocent bystander after reading the high and low confidence incorrect co-witness statements were compared using a between-subjects t-test. It was found participants who blamed the innocent bystander had equivalent levels of confidence in their judgements irrespective of whether they read a high confidence $(M=7.20, S D=2.18)$ or low confidence $(M=6.60, S D=2.72)$ cowitness statement, $t(23)=.61, p=.55, d=0.24$. An additional exploratory test was also conducted comparing the confidence of participants who blamed the innocent bystander and those who did not in the incorrect statement condition only, irrespective of whether they worked with a high or low confidence co-witness. It was found that those who blamed he innocent bystander had lower confidence in their judgements $(M=6.96, S D=2.37)$ than those who did not $(M=9.15, S D=1.74)$, $t(82)=4.72, p<0.05, d=1.05$. Combined, these results offer no evidence of confidence conformity amongst those who engaged in blame conformity. They do, however, show that those who engaged in blame conformity after reading an incorrect statement were less confident in their blame judgements than those who did not engage in blame conformity after reading an incorrect statement.

\section{Study 2}

Study 2 examined whether or not eyewitnesses with higher general self-confidence, compared to those with lower general self-confidence, are at less risk of blaming an innocent bystander for a crime after reading an incorrect co-witness statement that suggests the innocent bystander was the perpetrator.

\section{Method}

\section{Participants}

There were 240 participants, aged 18-78 ( $M=36.67, S D=10.88 ; 49.60 \%$ male, $50.40 \%$ female). They were recruited via Amazon’s Mechanical Turk using the same criteria as Study 1 and were paid US\$2.50.

\section{Design}

This study had a 3 x 2 between-subjects design. The first factor was co-witness statement type (a control statement, a correct statement, or an incorrect statement). The second factor was the 
participants' level of general self-confidence as determined by their scores on the Personal Evaluation Inventory (PEI: Shrauger \& Schohn, 1995). For this, the participants were classed as highest in general self-confidence if their scores were above the median and lowest in general selfconfidence if their scores were at or below the median. The PEI is described in the Stimuli section and the procedure for creating the median split is described in the Results section. As in Study 1, the dependent measures in this study were participants' attributions of blame for the crime and their confidence in these attributions.

\section{Stimuli}

Study 2 utilised the same crime video, two filler videos, and 10-item recognition memory test about the crime video as Study 1 . Novel to this study was the use of the PEI to assess participants' levels of general self-confidence. The PEI is a 54 item self-report questionnaire with eight subscales. Six subscales are designed to assess college student’s specific self-confidence across six domains (e.g., physical appearance; speaking to groups). A seventh subscale assesses respondents’ current mood. Of most relevance here is the eighth subscale, which assesses respondents' general self-confidence. The general self-confidence subscale can be used as a reliable measure of self-confidence in any population and not just college students (Stankov, Kleitman, \& Jackson, 2014). As our sample in this study likely contained non-college students, only the results from general self-confidence subscale were analysed. This subscale contains seven items. Example items include "I have fewer doubts about my abilities than most people" and "If I were more confident about myself, my life would be better". Each item on this subscale is rated on a 4-point Likert scale that ranges from Strongly Agree to Strongly Disagree. Scores on the general selfconfidence subscale are summed across items, meaning that they range from 7 to 28 . Higher scores indicate greater general self-confidence. The PEI has good reliability and validity (see Shrauger \& Schohn, 1995; Stankov et al., 2014).

The co-witness statement used in Study 2 was near identical to that from Study 1 . The only difference was that the security guard did not ask the co-witness how confident she was in her 
statement (and the co-witness offered no indication as to how confident she was). This meant that there were only three statement types in Study 2 (a control statement, a correct statement, and an incorrect statement).

\section{Results and Discussion}

\section{Blame conformity analysis}

A median split of the general self-confidence sub-scale scores on the PEI was used as the basis for dividing participants into those with highest and lowest general self-confidence. The median value for participants' scores on this scale was $17(M=17.35, S D=4.65)$. Those who scored above the median ( $55.40 \%$ of the sample) were classed as having the highest self-confidence whereas those equal to or below median were classed as having the lowest self-confidence. We emphasise that we are not classifying the former as having high self-confidence and the latter as having low self-confidence as no cut-off points for such classifications exist. Instead, we are using the more conservative terms "highest self-confidence" and "lowest self-confidence" to reflect the fact that this division is being made arbitrarily. The final sample contained 35 participants in the highest self-confidence control statement condition, 39 in the highest self-confidence correct statement condition, 43 in the highest self-confidence incorrect statement condition, 45 in the lowest self-confidence control statement condition, 41 in the lowest self-confidence correct statement condition, and 37 in the lowest self-confidence incorrect statement condition.

Two 4 x 3 Exact Pearson Chi-Square tests were conducted to ascertain if there was an association between who participants blamed for the crime (the innocent bystander, the perpetrator, neither, or don't know) and who the co-witness blamed for the crime (nobody, the innocent bystander, the perpetrator). The first test examined attributions of blame of those participants with the highest self-confidence and second examined attributions of blame of those participants with the lowest self-confidence. The full range of observed frequencies (as percentages) are in Table 2.

After reading the control co-witness statement, $8.60 \%$ of participants with highest selfconfidence blamed the innocent bystander for the crime whereas $85.70 \%$ blamed the perpetrator. 
Similarly, after reading the correct co-witness statement, $5.10 \%$ of participants with the highest selfconfidence blamed the innocent bystander and 94.90\% blamed the perpetrator. The participants with the highest self-confidence were therefore largely correct in their attributions of blame in these conditions. In contrast, when they read the incorrect co-witness statement, $16.30 \%$ of these participants blamed the innocent bystander and $81.40 \%$ blamed the perpetrator. There was therefore a general trend towards participants with the highest self-confidence engaging in blame conformity after reading an incorrect co-witness statement. Despite this, there was no significant association between who the co-witness blamed for the crime and who participants with the highest selfconfidence blamed, $\chi^{2}(6, n=117)=6.43$, exact $p=.38$, Cramer's $V=.17$.

After reading the control co-witness statement, $4.44 \%$ of participants with lowest selfconfidence blamed the innocent bystander for the crime and $95.60 \%$ blamed the perpetrator. Similarly, after reading correct co-witness statement, $2.40 \%$ of participants with the lowest selfconfidence blamed the innocent bystander and $92.70 \%$ blamed the perpetrator. The participants with the lowest self-confidence were therefore largely correct in their attributions of blame in these conditions. In contrast, when they read the incorrect co-witness statement, 32.40\% blamed the innocent bystander and $62.20 \%$ blamed the perpetrator. There was therefore a trend towards these participants engaging in blame conformity. In line with this, there was a significant association between who the co-witness blamed for the crime and who participants with the lowest selfconfidence blamed for the crime, $\chi^{2}(6, n=123)=25.43$, exact $p<.001$, Cramer's $V=.32$. The standardised residuals revealed that after reading an incorrect co-witness statement blaming the innocent bystander for the crime, those participants with the lowest self-confidence blamed the innocent bystander more often than expected $(z=3.50)$. No other cells contained values that significantly differed from the expected frequencies (all z’s $=<1.96$ ).

One limitation of using a median split to divide participants into those with the highest and lowest general self-confidence is that those just above the median and those at or just below the median were categorised differently despite having similar levels of general self-confidence. To 
ensure the effects of general self-confidence on blame conformity were not an artefact of this split, a binary logistic regression was conducted with general self-confidence scores as the predictor variable and blame (perpetrator or innocent bystander) as the outcome variable. After reading an incorrect co-witness statement, general self-confidence predicted blame $\chi^{2}(1, N=77)=7.51$, $p<.05$, with the model explaining between $0.09 \%$ and $0.14 \%$ of the variance (Cox \& Snell $\mathrm{R}^{2}$ and Nagelkerke $\mathrm{R}^{2}$, respectively). More specifically, increases in general self-confidence reduced the odds of blaming the innocent bystander for the crime $(\operatorname{Exp}(B)=.86)$.

Combined, the above results demonstrate that participants with the lowest general selfconfidence were at greatest risk of engaging in blame conformity. Moreover, those with the highest general self-confidence (above the median) were at no greater risk of blaming the innocent bystander for the crime after reading an incorrect co-witness statement than those who read a correct or control co-witness statement.

\section{INSERT TABLE 2 HERE}

\section{Blame confidence analysis}

In an exploratory analysis, a Pearson's Product-Moment Correlation was used to test for a relationship between participants general self-confidence scores and their confidence in their incorrect blame judgements in the incorrect statement condition. No significant correlation was found, $r=.04, n=19, p=.85$. To fully explore why this was the case, a 2 (general self-confidence: highest vs. lowest) x 2 (blame judgement: innocent bystander vs. perpetrator) between-subjects ANOVA was conducted. There was a main effect of blame judgment, with those who blamed the innocent bystander $(M=5.95, S D=2.95)$ being less confident in their decision than those who blamed the perpetrator $(M=8.97, S D=1.82), F(1,73)=31.53, M S e=4.54, p<.001, \eta_{p}^{2}=.30$. There was no significant main effect of general self-confidence and no significant interaction (both $p$ 's $>.05)$. These results show that participants who engaged in blame conformity after reading an incorrect co-witness statement were equally confident in their blame judgements irrespective of whether or not they had the highest or lowest general self-confidence. They were, however, also 
less confident in their blame judgements than those who correctly blamed the perpetrator.

\section{General Discussion}

Memory conformity refers to the act of altering one's account of an event to be consistent with another's differing account of the same event. In two studies, we examined whether or not the degree to which participant eyewitnesses engage in a specific form of memory conformity known as blame conformity, whereby they blame an innocent bystander for a crime after reading an incorrect co-witness statement suggesting this person was the perpetrator, is influenced by the level of confidence the co-witness expresses in her incorrect statement (Study 1) and an eyewitness's own level of general self-confidence (Study 2). Participants’ confidence levels in their blame judgements were also assessed.

\section{Co-witness confidence}

It was previously known that participants are more likely to engage in memory conformity with a confederate during a collaborative remembering task when the confederate expresses a high level of confidence, compared to a low level of confidence, in his or her inaccurate recollections (Goodwin et al., 2013; Ost et al., 2008; Wright et al., 2000). Goodwin et al., however, also found little evidence of memory conformity, irrespective of co-witness confidence, when participants were subsequently tested alone. This latter finding is unusual as memory conformity typically occurs when participants are tested alone (see Gabbert et al., 2012; Wright et al., 2009). Blame conformity also occurs when participants are tested alone (Thorley, 2015, Thorley \& RushtonWoods, 2013). Study 1 therefore re-examined the impact of an inaccurate co-witness's confidence on participants’ memory reports of events when they are tested alone (using a blame conformity paradigm) in case the lack of memory conformity observed by Goodwin et al. was peculiar to their study. We found that blame conformity did occur when participants were tested alone. This occurred irrespective of the inaccurate co-witness's confidence, though the effect was larger when participants were exposed to a highly confident co-witness.

Goodwin et al. (2013) also found that participants’ confidence levels during their 
collaborative remembering test mirrored those of the confederate, suggesting a confidence conformity effect. Unsurprisingly, they found no such effect when participants were tested alone (as no memory conformity was observed). In our Study 1, participants who engaged in blame conformity with the incorrect co-witness, irrespective of how confident the co-witness was, had moderate levels of confidence in their blame judgements. Moreover, they were significantly less confident than those who did not engage in blame conformity.

It is likely our findings conflict with those of Goodwin et al. (2013) as participants in both studies engaged in memory conformity/blame conformity for different reasons. Goodwin et al. suggest their participants engaged in memory conformity and confidence conformity during their collaborative remembering task as a result of normative influence, meaning that they knew the confederate was wrong but conformed in order to avoid a disagreement. This effect then disappeared on the post-collaborative individual memory test when there was no opportunity for disagreement. It is unlikely our participants engaged in blame conformity as a result of normative influence as they always worked alone and there was no confederate to disagree with. It seems more likely that participants in Study 1 engaged in blame conformity as a result of informational influence, whereby they were unsure if the incorrect co-witness statement was correct but conformed anyway in case it was. When the co-witness was not very confident, the participants may have felt more comfortable dismissing her PEM as potentially incorrect and blaming the perpetrator. When the co-witness very confident, however, the participants may have felt more inclined to trust her PEM and blame the innocent bystander. Support for this suggestion comes from earlier work showing that people perceive highly confident eyewitnesses as more accurate than less confident eyewitnesses (see Penrod \& Cutler, 1995) and they trust the testimony of very confident but inaccurate eyewitnesses over that of less confident but more accurate eyewitnesses (Brewer \& Burke, 2002; Lindsey et al., 1981). An informational influence explanation is also supported by our observation that participants who engaged in blame conformity had less confidence in their blame attributions than those who did not, suggesting that they had doubts over whether or not the 
incorrect co-witness statement was correct but blamed the innocent bystander for the crime anyway.

It is important to acknowledge that not all participants who engaged in blame conformity may have done so as a result of informational influence. We cannot rule out the possibility that some engaged in blame conformity as they developed false memories of the innocent bystander committing the crime. Memory conformity can occur as a result of both informational influence and false remembering within the same study (Gabbert et al., 2007; Meade \& Roediger, 2002). Future research establishing the rate of false remembering (if any occurs) would be beneficial.

\section{Eyewitness self-confidence}

Prior to Study 2, little was known about the impact of eyewitnesses own general selfconfidence on their susceptibility to memory conformity/blame conformity. Vrij and Bush (2000) had previously shown that children with higher self-confidence are less likely to answer misleading questions inaccurately, although self-confidence was not assessed in their study using a validated measure. Study 2 extends their finding by showing that adults who are highest in general selfconfidence, as assessed using a validated measure, are less likely to engage in blame conformity than those who are lowest in general self-confidence. It may be the case that individuals higher in general self-confidence have more self-belief in their own memory and are less likely to engage in memory conformity/blame conformity with a source when they are unsure of its accuracy. From a theoretical perspective, this finding is important as it identifies a previously unidentified moderator of memory conformity/blame conformity.

Those participants who engaged in blame conformity were equivalent in terms of the confidence they expressed in their incorrect blame judgements, irrespective of how much selfconfidence they had. As in Study 1, however, these participants were less confident in their judgements than those who did not engage in blame conformity after reading an incorrect cowitness statement. This suggests that they did not fully trust the co-witness statement but they conformed regardless. Again, this is consistent with an informational influence explanation for the blame conformity observed here (but we cannot rule out the possibility that some participants had 
false memories of the innocent bystander committing the crime).

\section{Limitations}

One limitation to the ecological validity of these studies is the way in which memory of the perpetrator was assessed. Here, participants answered a multiple choice recognition test question about who committed the crime. This test was used to ensure each participant was questioned about the perpetrator's identity in an identical way. Real police interviewers, however, are unlikely to ask eyewitnesses multiple choice questions. Instead, guidelines in many countries recommend they first ask eyewitnesses to freely the recall a crime and then ask them specific cued recall questions about it (e.g., for the United States, see National Institute of Justice, 1999, 2002; for the United Kingdom, see Ministry of Justice, 2011). Free recall typically produces accurate recollection as it requires selfguided retrieval, meaning eyewitnesses only report information they are confident about (Koriat \& Goldsmith, 1994, 1996). In contrast, multiple choice tests utilise externally-guided retrieval where the interviewer decides which information the eyewitness needs to remember. Externally-guided retrieval can increase recollection errors and confabulations as eyewitnesses are forced to try and remember information they may be unsure of. It is possible that asking our participants a multiple choice question about who committed the crime, when one option was the innocent bystander, facilitated blame conformity so that it reached levels that would not have been observed during a free recall test. To control for this, one of the response options to the multiple choice questions in both studies was 'don't know'. This is forensically important as real eyewitnesses can refrain from answering a question during an interview if they are unsure of the answer (Roebers \& Fernandez, 2002). It is also methodologically important as providing this option during multiple choice recognition tests increases memory accuracy (e.g., Kelley \& Sahakyan, 2003; Koriat \& Goldsmith, 1994, 1996; Scoboria, Mazzoni, \& Kirsch, 2008). Thus, whilst the ecological validity of this study may have been lowered by using a multiple choice question to assess memory of the perpetrator, it is unlikely that this question increased susceptibility to blame conformity. 
It is also acknowledged that the generalisability of the blame conformity effect may be limited to instances where there is a degree of similarity between the innocent bystander and the perpetrator. Eyewitnesses are more likely to spontaneously blame an innocent bystander for a crime if this person resembles the perpetrator (Read, Tollestrup, Hammersley, McFadzen, \& Christensen, 1990). In the current studies, blame for an incident was shifted between two people who were similar in terms of their gender, race, and age. It may be case that these ethnographic similarities facilitated blame conformity as participants felt they may have simply misremembered which young white male committed the crime. There were, however, several differences between the perpetrator and innocent bystander such as their clothing, hairstyle, and build. Several other salient differences, such as their gender or race, could have also existed between them. It would be of interest to determine whether or not blame conformity still occurs when more salient differences exist between an innocent bystander and a perpetrator.

\section{Conclusion}

The current studies showed that participants are at risk of blaming an innocent bystander for a crime after reading an incorrect co-witness statement blaming this person for the crime. Moreover, this effect is greater when the co-witness expresses a high level of confidence, compared to a low level of confidence, in the accuracy of her incorrect statement, and when participants are low, compared to high, in general self-confidence. Participants who blame an innocent bystander are also less confident in their decisions that those who do not blame an innocent bystander, suggesting an awareness that these incorrect attributions may be incorrect. 


\section{References}

Blank, H., Ost, J., Davies, J., Jones, G., Lambert, K., \& Salmon, K. (2013). Comparing the influence of directly vs. indirectly encountered post-event misinformation on eyewitness remembering. Acta Psychologica, 144, 635-641. doi:10.1016/j.actpsy.2013.10.006

Borchard, E.M. (1932). Convicting the innocent: Sixty -five actual errors of criminal justice. New York: Garden City Publishing Company.

Brewer, N., \& Burke, A. (2002). Effects of testimonial inconsistencies and eyewitness confidence on mock-juror judgments. Law and Human Behavior, 26, 353-364. doi:10.1023/A:1015380522722.

Buckhout , R. (1974). Eyewitness testimony. Scientific American, 231, 23-31

Casler, K., Bickel, L., \& Hackett, E. (2013). Separate but equal? A comparison of participants and data gathered via Amazon’s MTurk, social media, and face-to-face behavioral testing. Computers in Human Behavior, 29, 2156-2160. doi:10.1016/j.chb.2013.05.009

Davis, D., \& Loftus, E. (2007). Internal and external sources of misinformation in adult witness memory. In M. P. Toglia, J. D. Read, D. F. Ross, \& R. C. L. Lindsay (Eds.), Handbook of eyewitness psychology. Volume 1: Memory for events (pp. 195-237). Mahwah, New Jersey: Lawrence Erlbaum.

Field, A. (2013). Discovering statistics using IBM SPSS statistics. London: Sage.

Gabbert, F., Memon, A., \& Allan, K. (2003). Memory conformity: Can eyewitnesses influence each other’s memories for an event? Applied Cognitive Psychology, 17, 533-543. doi:10.1002/acp.885

Gabbert, F., Memon, A., Allan, K., \& Wright, D. B. (2004). Say it to my face: Examining the effects of socially encountered misinformation. Legal \& Criminological Psychology, 9, 215227. doi: $10.1348 / 1355325041719428$

Gabbert, F., Memon, A., \& Wright, D. B. (2007). I saw it for longer than you: The relationship 
between perceived encoding duration and memory conformity. Acta Psychologica, 124, 319-331. doi:10.1016/j.actpsy.2006.03.009

Gabbert, F., Wright, D. B., Memon, A., Skagerberg, E. M., \& Jamieson, K. (2012). Memory conformity between eyewitnesses. Court Review, 48, 36-138.

Garrett, B. (2011). Convicting the innocent. Cambridge, Massachusetts: Harvard University Press.

Goodwin, K. A., Kukucka, J. P., \& Hawks, I. M. (2013). Co-Witness Confidence, Conformity, and Eyewitness Memory: An Examination of Normative and Informational Social Influences. Applied Cognitive Psychology, 27, 91-100. doi:10.1002/acp.2877

Innocence Project (2015). Retrieved December 29th, 2015, from http://www.innocence project.org/cases-false-imprisonment/front page\#c10=published\&b_start=0\&c4= Exonerated+by+DNA

Kelley, C. M., \& Sahakyan, L. (2003). Memory, monitoring, and control in the attainment of memory accuracy. Journal of Memory and Language, 48, 704-721. doi:10.1016/S0749596X(02)00504-1

Koriat, A., \& Goldsmith, M. (1994). Memory in naturalistic and laboratory contexts: distinguishing the accuracy-oriented and quantity-oriented approaches to memory assessment. Journal of Experimental Psychology: General, 123, 297-315. doi:10.1037/0096-3445.123.3.297

Koriat, A., \& Goldsmith, M. (1996). Monitoring and control processes in the strategic regulation of memory accuracy. Psychological Review, 103, 490-517. doi: 10.1037/0033295X.103.3.490

Lampinen, J. M., Neuschatz, J. S., \& Cling, A. D. (2012). The Psychology of Eyewitness Identification. London: Taylor \& Francis.

Lindsay, R. C., Wells, G. L., \& Rumpel, C. M. (1981). Can people detect eyewitnessidentification accuracy within and across situations?. Journal of Applied Psychology, 
66, 79 -89. doi:10.1037/0021-9010.66.1.79.

Loftus, E. F., Donders, K., Hoffman, H. G., \& Schooler, J. W. (1989). Creating new memories that are quickly accessed and confidently held. Memory and Cognition, 17, 607616. doi:10.3758/BF03197083

Loftus, E. F., Miller, D. G., \& Burns, H. J. (1978). Semantic integration of verbal information into a visual memory. Journal of Experimental Psychology: Human Learning and Memory, 4, 19-31. doi:10.1037/0278-7393.4.1.19.

Luna, K., \& Migueles, M. (2009). Acceptance and confidence of central and peripheral misinformation. The Spanish Journal of Psychology, 12, 405-413. doi: $10.1017 / \mathrm{S} 1138741600001797$

Luus, C. A., \& Wells, G. L. (1994). The malleability of eyewitness confidence: Co-witness and perseverance effects. Journal of Applied Psychology, 79(5), 714 -723. doi = 10.1037/0021-9010.79.5.714

Meade, M. L., \& Roediger, H. L. (2002). Explorations in the social contagion of memory. Memory and Cognition, 30, 995-1009. doi:10.3758/BF03194318

Mehta, C. R., \& Patel, N. R. (2011). IBM SPSS Exact Tests. Retrieved from http://www.sussex.ac.uk/its/pdfs/SPSS_Exact_Tests_21.pdf

Ministry of Justice (2011). Achieving best evidence in criminal proceedings: Guidance on interviewing victims and witnesses, and using special measures. Retrieved January $7^{\text {th }}, 2016$, from: www.cps.gov.uk/publications/prosecution/victims.html

National Institute of Justice (1999). Eyewitness evidence: A guide for law enforcement. Retrieved January $7^{\text {th }}$, 2016, from https://www.ncjrs.gov/pdffiles1/nij/178240.pdf National Institute of Justice. Eyewitness evidence: A trainer’s manual for law enforcement (2002). Retrieved January $7^{\text {th }}$, 2016, from https://www.ncjrs.gov/nij/eyewitness/188678.pdf

Oney, E., \& Oksuzoglu-Guven, G. (2015). Confidence: A critical review of the literature and 
an alternative perspective for general and specific self-confidence. Psychological Reports, 116, 149-163. doi:10.2466/07.PR0.116k14w0

Ost, J., Ghonouie, H., Cook, L., \& Vrij, A. (2008). The effects of confederate influence and confidence on the accuracy of crime judgements. Acta Psychologica, 128, 25-32. doi:10.1016/j.actpsy.2007.09.007

Paolacci, G., \& Chandler, J. (2014). Inside the turk understanding mechanical turk as a participant pool. Current Directions in Psychological Science, 23, 184-188. doi: $10.1177 / 0963721414531598$

Paterson, H. M., \& Kemp, R. I. (2006a). Co-witnesses talk: A survey of eyewitness discussion. Psychology, Crime, \& Law, 12, 181-191. doi:10.1375/pplt.12.2.424

Paterson, H. M., \& Kemp, R. I. (2006b). Comparing methods of encountering post-event information: the power of co-witness suggestion. Applied Cognitive Psychology, 20, 10831099. doi: 10.1002/acp.1261

Penrod, S., \& Cutler, B. (1995). Witness confidence and witness accuracy: Assessing their forensic relation. Psychology, Public Policy, and Law, 1, 817-845. doi:10.1037/10768971.1.4.817

Porter, C. (2007). The conviction of the innocent: How the law can let us down. Australia: Random House.

Read, J. D., Tollestrup, P., Hammersley, R., McFadzen, E., \& Christensen, A. (1990). The unconscious transference effect: Are innocent bystanders ever misidentified?. Applied Cognitive Psychology, 4, 3-31. doi: 10.1002/acp.2350040103

Roebers, C. M., \& Fernandez, O. (2002). The effects of accuracy motivation on children's and adults' event recall, suggestibility, and their answers to unanswerable questions. Journal of Cognition \& Development, 3, 415-443. doi: 10.1080/15248372. 2002.9669676

Roediger, H. L., Meade, M. L., \& Bergman, E. T. (2001). Social contagion of memory. Psychonomic Bulletin \& Review, 8, 365-371. doi: 10.3758/BF03196174 
Scoboria, A., Mazzoni, G., \& Kirsch, I. (2008). " Don't know" responding to answerable and unanswerable questions during misleading and hypnotic interviews. Journal of Experimental Psychology: Applied, 14, 255 -265. doi:10.1037/1076-898X.14.3.255.

Shrauger, J. S., \& Schohn, M. (1995). Self-confidence in college students: Conceptualization, measurement, and behavioral implications. Assessment, 2, 255-278. doi: $10.1177 / 1073191195002003006$

Skagerberg, E. M., \& Wright, D. B. (2008). The prevalence of co-witnesses and co-witness discussions in real eyewitnesses. Psychology, Crime, \& Law, 14, 513-521. doi:10.1080/10683160801948980

Stankov, L., Kleitman, S., and Jackson, S. A. (2014). Measures of the trait of confidence. In G. J. Boyle, D. H. Saklofske and G. Matthews (Eds.), Measures of personality and social psychological constructs (pp. 158-189). London: Academic Press.

Thorley, C. (2013). Memory conformity and suggestibility. Psychology, Crime \& Law, 19, 565575. doi:10.1080/1068316X.2011.648637

Thorley, C. (2015). Blame conformity: Innocent bystanders can be blamed for a crime as a result of misinformation from a young, but not elderly, adult co-witness. PLoS ONE, 10, e0134739. doi:10.1371/journal.pone.0134739

Thorley, C., \& Rushton-Woods, J. (2013). Blame conformity: Leading eyewitness statements can influence attributions of blame for an accident. Applied Cognitive Psychology, 27, 291296. doi:10.1002/acp.2906

Vrij, A., \& Bush, N. (2000). Differences in suggestibility between 5-6 and 10-11 year olds: The relationship with self confidence. Psychology, Crime and Law, 6, 127-138. doi: $10.1080 / 10683160008410837$

Williams, R., \& Johnson, P. (2013). Genetic policing: The uses of DNA in police investigations. Cullompton: Willan.

Wright, D. B., Memon, A., Skagerberg, E. M., \& Gabbert, F. (2009). When eyewitnesses 
talk. Current Directions in Psychological Science, 18, 174-178. doi:10.1111/j.14678721.2009.01631.x

Wright, D. B., Self, G., \& Justice, C. (2000). Memory conformity: Exploring misinformation effects when presented by another person. British Journal of Psychology, 91, 189202. doi:10.1348/000712600161781 


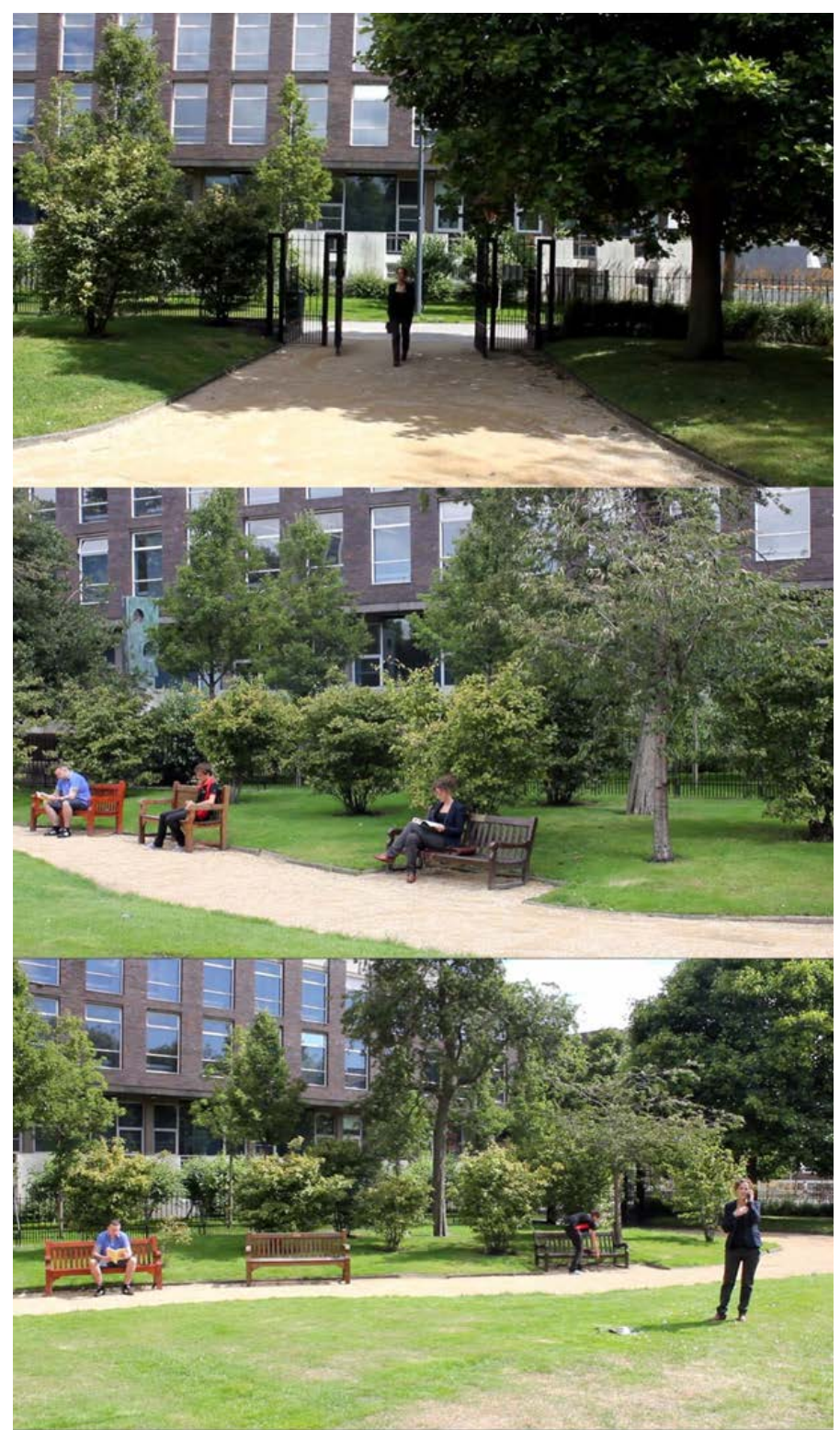

Figure 1. Three screenshots from the crime video. The top pane shows the female victim entering the park, the middle pane shows the victim sat on a bench reading a book whilst the innocent bystander (furthest left) and perpetrator are sat nearby, and the bottom pane shows the victim using her phone as the perpetrator steals her bag. 
Table 1

Percentage of trials on which participants placed blame for a crime onto the perpetrator, innocent bystander, neither person, or responded don't know after reading a co-witness statement where a high-confidence or low-confidence co-witness blamed the perpetrator, blamed the innocent bystander, or blamed no-one (control). The percentages shown are within-statement type.

\section{$\underline{\text { Perpetrator }} \quad \underline{\text { Innocent Bystander }} \quad$ Neither $\quad$ Don't Know}

\begin{tabular}{|c|c|c|c|c|c|}
\hline \multirow[t]{3}{*}{ Low } & Correct & 86.36 & 6.82 & 2.27 & 4.54 \\
\hline & Incorrect & 73.33 & 22.22 & 0.00 & 4.44 \\
\hline & Control & 82.22 & 6.67 & 0.00 & 11.11 \\
\hline \multirow[t]{3}{*}{ High } & Correct & 97.83 & 2.17 & 0.00 & 0.00 \\
\hline & Incorrect & 59.09 & 34.09 & 4.54 & 2.27 \\
\hline & Control & 83.33 & 8.33 & 0.00 & 8.33 \\
\hline
\end{tabular}


Table 2

Percentage of trials on which participants who were lowest or highest in general self-confidence placed blame for a crime onto the perpetrator, innocent bystander, neither person, or responded don't know after reading a statement about the crime from a co-witness who blamed the perpetrator, blamed the innocent bystander, or blamed no-one (control). The percentages shown are within-statement type.

Confidence Statement Type

Participant Blame

\section{Perpetrator Innocent Bystander $\quad$ Neither $\quad$ Don't Know}

Low

Correct

92.70

2.40

0.00

Incorrect

62.20

32.40

2.70

2.70

Control

95.60

4.40

0.00

0.00

High

Correct

94.90

5.10

0.00

0.00

Incorrect

81.40

16.30

0.00

2.30

Control*

85.70

8.60

2.90

2.90

Table note: Row denoted * does not equal $100 \%$ due to rounding up. 


\section{Footnote}

${ }^{1}$ Previous studies have found no evidence of a relationship between memory ability when recollecting information and susceptibility to memory conformity/blame conformity in relation to that same information (e.g., Gabbert, Memon, \& Allan, 2003; Thorley, 2013, Thorley \& RushtonWoods, 2013). 